\title{
The biology business
}

In the first two articles of our special section, we look at the industrial potential of biotechnology and who is likely to exploit it first. Professor Brian Hartley of Imperial College, London is optimistic that it will be applied rapidly to many industries - he outlines its promise below. And opposite, Robert Walgate compares the efforts of different countries throughout the world

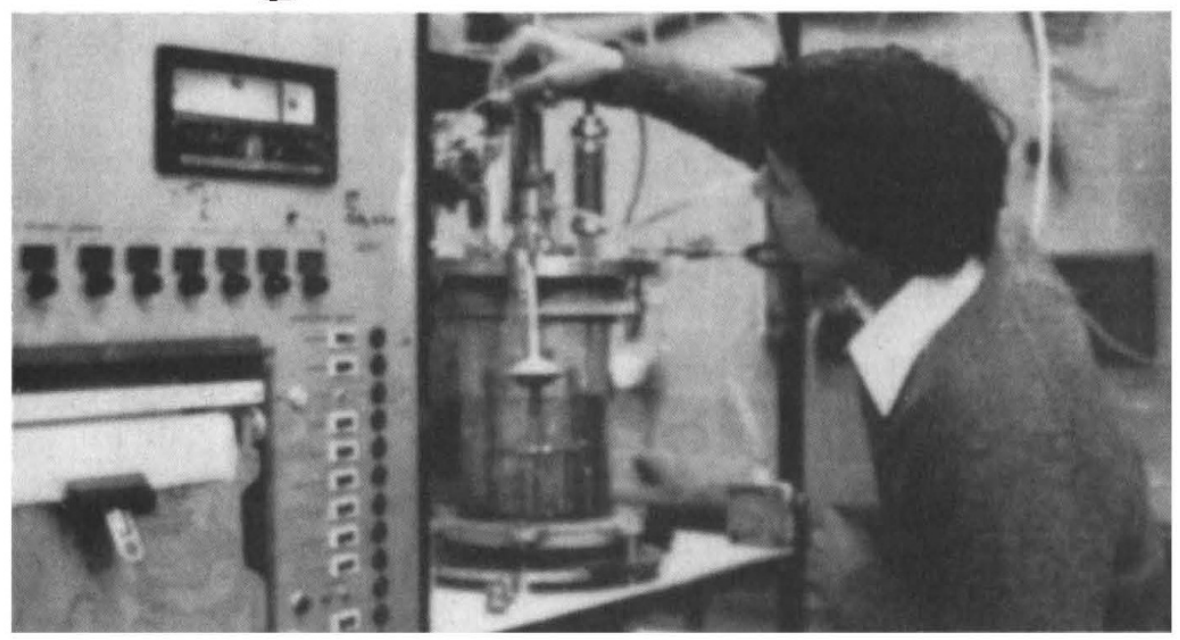

Tuning fermentation conditions before pilot plant trails

\section{The bandwagon begins to roll}

WHY should industry and governments think seriously of investing in biotechnology?

First is the tremendous rate of development of the technology itself. Five years ago, even optimists would have predicted that it would be a decade before genetic engineering could be commercially exploited, but this is about to be disproved. The earliest prospect is for new pharmaceuticals made cheaply by fermentation. Human hormones, enzymes or antibodies will replace animal products or create new therapies. Already bacterial fermentation processes for human somatostatin, growth hormone and insulin are patented and there is a world-wide chase for cheap interferon, potentially the wonder-drug of the 80 s. Less dramatic, but equally important, is the prospect of new, cheap, safe and effective vaccines. By separating the gene for a viral antigen from the toxic or infective components, this harmless protein could be made cheaply by a microorganism. Such inherently safe products should also reduce expensive toxicity testing. Already progress is reported towards hepatitis $B$ and influenza vaccines, and one can envisage that even measles and the common cold may succumb. Cheap animal vaccines will increase agricultural productivity: the prospects of such vaccines for foot and mouth disease or swine fever now merit consideration of programmes to eradicate these diseases.

Genetic engineering also offers new diagnostic tools to medicine. Enzyme or antibody diagnostic kits for the general practitioner are already a thriving business, and genetic engineering promises novel and cheaper products. Tiny amounts of the DNA or RNA of viruses and microorganisms can now be readily mapped, isolated, sequenced and replicated. Thus new subtypes of viruses can be recognised by their different DNA sequences and "probes" of DNA complementary to these will be invaluable in diagnosis and epidemiology.

The second major factor favouring biotechnology is the dramatic shift in terms of trade, and in public opinion, from fossil fuels to renewable energy resources. Environmental pressures have also forced up the costs of disposal of agricultural and industrial wastes: biotechnology can help by converting these into useful products. The simplest conversion is into microorganisms for animal feed (Single Cell Protein: SCP). For example, a British Petroleum process utilises n-alkanes - a side product of oil refining; a Shell process uses methane, also frequently wasted in oil recovery, and Imperial Chemical Industries grow organisms on methanol obtained from methane. Only the latter is currently judged economic, and then only by virtue of large-scale centralised production.

As petrochemicals become more expensive there are even brighter prospects for biotechnology in production of bulk chemicals. Japan has led the way with a profitable fermentation industry producing amino acids, nucleotides and organic acids, but this relies largely on conventional microbiology, genetics and fermentation feedstocks. It can certainly be challenged by new biotechnology applied to new sources of biomass. Indeed since many microbial products - proteins, polysaccharides, organic acids, for example - could be produced more cheaply than petrochemicals, should we not visualise new biopolymers, biosolvents, and biodetergents?

In this light, enzyme technology will surely take off. Genetic engineers already have ways to persuade microbes to superproduce enzymes of choice and even to secrete them into the medium. Alternatively the superproduced enzymes can be retained within the cell, so that the immobilised cell itself becomes a fixed catalyst. An early example is the ICI process for producing high fructose syrups with immobilised glucose isomerase. This has received the EEC seal of approval by earning a tariff because it competes effectively with sugar beet. Enzymes embedded in membranes can form enzyme electrodes for continuous monitoring of flow processes, and one can foresee membranes that are specifically permeable to a single compound.

Not least is the contribution that biotechnology may make to the world's energy problem. In hot, sticky countries such as Brazil, big schemes are already afoot for producing ethanol from sugar cane or cassava, as a fuel for cars. Moreover big improvements on the current conventional fermentation can be expected; for example, a rapid continuous fermentation by organisms living at high temperatures that would harness the heat of fermentation to distil the ethanol. Thus as the price of oil continues to soar, the Brazilian adventure seems to be far from a risk. Indeed, Western developed countries are beginning to examine their own resources of biomass for energy; industrial and agricultural wastes are an obvious target and, just around the corner are processes for converting cellulose into liquid or gaseous fuels. Then a really balanced alternative to our oil-based economy will have arrived. 